\title{
Poaching: A Threat for Vulnerable Wild Animal Species in Oman
}

\author{
Massimo Giangaspero ${ }^{1^{*}}$ and Metab Khalaf Salim Al Ghafri ${ }^{2}$ \\ ${ }^{1}$ Faculty of Veterinary Medicine, University of Teramo, Italy \\ ${ }^{2}$ Diwan of the Royal Court, Office for Conservation of the Environment, Al Wasta Wildlife Reserve, Oman \\ *Corresponding author: Massimo Giangaspero, Faculty of Veterinary Medicine, Piazza Aldo Moro 45, 64100 Teramo, Italy, Tel: 0033450392875; E-mail: \\ giangasp@gmail.com
}

Received date: July28, 2014, Accepted date: October 02, 2014, Published date: October 06, 2014

Copyright: (C) 2014 Massimo Giangasperoet al. This is an open-access article distributed under the terms of the Creative Commons Attribution License, which permits unrestricted use, distribution, and reproduction in any medium, provided the original author and source are credited.

\begin{abstract}
Despite international and national control measures, poaching is still reported worldwide, with variable intensity and impact against wildlife in the different geographic region ecosystems. In Oman, poaching adversely affected vulnerable species such as Arabian oryx (Oryx leucoryx) and Sand gazelle (Gazella subgutturosa). Also sharks become victims of illegal fishing for fin collection in relation to the high demand from oriental markets. People sensitization on the value of wildlife and the importance of natural patrimony preservation, combined with monitoring and repression of crimes against wildlife are essential elements to support conservation efforts especially for vulnerable and endangered species.
\end{abstract}

Keywords: Conservation; Poaching; Vulnerable wild animals

\section{Introduction}

Poaching is an illegal activity reported worldwide, with an impact against wildlife in the different geographic region ecosystems. The poaching related trade has intensified dramatically. The removal of animals from the wild for the pet trade is now considered a major threat to wild populations $[1,2]$ and animals have been exported so rapidly out of Southeast Asia to countries like the UK, US, and Japan that experts have coined the term "empty forest syndrome" to refer to the concomitant loss in biodiversity [3]. The estimation of the size of international trade in illegal wildlife is difficult and uncertain. However, despite enforcement of international and national norms, the International Criminal Police Association (Interpol) estimates that the illegal trade in wildlife, also a multi-billion dollar industry, is the second or third largest illegal industry in the world after drugs and arms [4]. The annual dollar value of illegal trade is somewhere between $\$ 5-\$ 20$ billion although there is no hard data supporting this claim [5].

Contemporary trade predominantly still flows from biodiversityrich, capital-poor countries to wealthy countries [6], especially for wildlife destined as companion animals. Apart from the trade of live animals, illegal hunting represents another large scale trade flow related to the demand of countries as China, in which an emerging new economy sustains the use of products such as rhinos' horns for traditional medicine or shark fins for culinary habits. Bear gall bladders get top dollar for Chinese herbal remedies, and big-horned sheep antlers can fetch $\$ 20,000$ on the black market. Therefore, for many poachers, profit is the main motive. But, in certain circumstances, poaching may also be due to poverty and wildlife is used for a local consumption in the framework of self-sustenance of defavorized rural communities. And, finally, illegal hunting may be perpetrated by some poachers that just love killing animals, or want a trophy.
The main problem is that poachers may also kill endangered species. With nearly one quarter of the world's mammals, one third of amphibians and more than one eighth of all bird species at risk of extinction [7], wildlife trade specifically threatens around one-third of bird and mammal species worldwide [8]. Furthermore, over exploitation of wildlife combined with poaching and illegal trade are capable of heavily depleting some wild animal species populations and even bringing some species close to extinction, and causing severe problems for the local ecosystem.

In the Sultanate of Oman, poaching adversely affected wildlife species such as Arabian oryx (Oryx leucoryx) and Sand gazelle (Gazella subgutturosa). Both species are listed as "vulnerable" (species as likely to become endangered unless the circumstances threatening its survival and reproduction improve), according to the Red List of Threatened Species issued by the International Union for the Conservation of Nature (IUCN), the world's main authority on the conservation status of species [9]. In particular, the Arabian oryx (Oryx leucoryx) or white oryx, the smallest member of Oryx genus, native to desert and steppe areas of the Arabian Peninsula, constitutes an important example of conservation efforts. It was extinct in the wild by the early 1970 s, but was saved in zoos and private preserves and reintroduced into the wild starting in 1980, and in 2011 it was the first animal to revert to vulnerable status after previously being listed as extinct in the wild. In 2011, populations were estimated at over 1,000 individuals in the wild, and 6,000-7,000 individuals in captivity worldwide. In 1994, the Sultanate of Oman allocated a wide area (2,700,000 hectares) destined for the reintroduction of the species in the central territory of the country [10]. Unfortunately, the species reintroduced in the wild suffered losses due to poaching. From about 400 oryx ranging freely in the desert by the year 1996, because of heavy hunting the population dropped to 138, of which only 28 were females, according to an estimation made in September 1998 [11]. Probably, this was due to the difficulties to monitor wide territories and not sufficient public sensitization on the value of wildlife vulnerable and endangered species and the importance of natural patrimony preservation. This obliged the authorities to move all the survived population in a restricted area under control at the conservation center of Al Wasta Wildlife Reserve. Currently, 514 white oryx are kept in captivity. In addition, 290 sand gazelles are present in the center. With concern to the sand gazelle populations, they have been subject to excessive hunting and poaching. This, combined with concomitant habitat degradation, resulted in an almost complete wipe-out of the wild species [12]. Probably, sand gazelles are no more present in the wild in Oman. No surveys have been recently conducted to confirm the suspicion in Omani desert territories such as the Empty Quarter and the Al Wahiba sands, sand gazelle specific ecosystems. However, this is 
suggested by the fact that no observations have been reported in the last years.

In perspective, repopulation is foreseen based on the breeding efforts conducted at the Al Wasta Wildlife Reserve. When the captive population will reach 500 animals, the reserve will release about 200 sand gazelles to the wild.

Even if in the country, as per Ministerial Decision, the hunting of all species of the wild is banned since 1993 [10], recent reports of law infringements recall attention on wildlife threatening. For example, two Arabian mountain gazelles (Gazella gazellacora) were poached in Al Saleel National Park in Al Kamil Wal Wafi area in May 2013, and in July 2013, other ten Arabian mountain gazelles have been illegally killed in the Wadi Khawan area at north-east of Muscat (Figure 1) [13]. Arabian mountain gazelles exist in the wild, but no estimation of their population in Oman is available. However, they are the favorite target for poachers because of their small size, and they can be caught easily by light trapping them at night. Even at the Al Wasta Wildlife Reserve 4 to 6 hunting incidents are reported yearly.

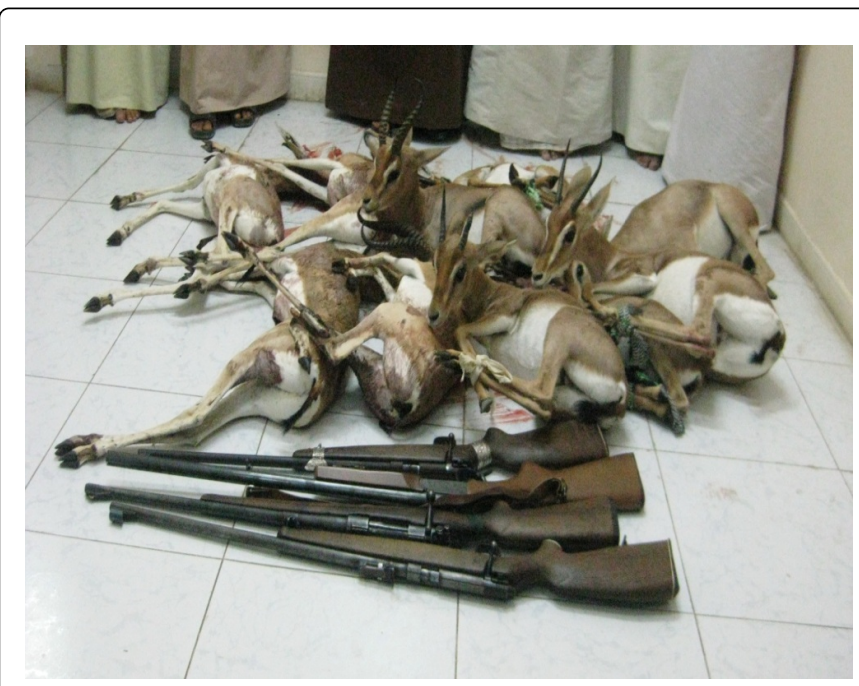

Figure 1: Arabian mountain gazelles (Gazella gazellacora) illegally killed in the Wadi Khawan area at north-east of Muscat, in July 2013 (photo courtesy of the Ministry Environment and Climate Affairs, Sultanate of Oman).

In the Sultanate of Oman, also sharks may become victims of illegal fishing for fins and tails collection in relation to the high demand from oriental markets, and therefore some shark bodies are wasted in this activity. The finding of sharks' fins and tails drying aside a coastal road, along with some quantity of abandoned fish, is suggestive of such illegal activity (Figure 2). With concern to the national fishery management of sharks and rays (species of the genus Elasmobranchii), almost all the catch is from traditional fishery using bottom lines and fixed gill nets. Rays are often caught incidentally by beach seines. Shark and ray total catch in 1998 was estimated at $4805 \mathrm{t}$ and $189 \mathrm{t}$, respectively [14]. Fisheries regulations prohibit the throwing of any shark part or shark waste in the sea or on shore. It also prohibit the handling, marketing or exporting of any shark part unless a licence is obtained from the competent authority. Enforcement of fisheries legislation is carried out by the Directorate General of Fisheries Resources, with the assistance of the Coast Guard of the Royal Oman Police and Royal Navy [14].
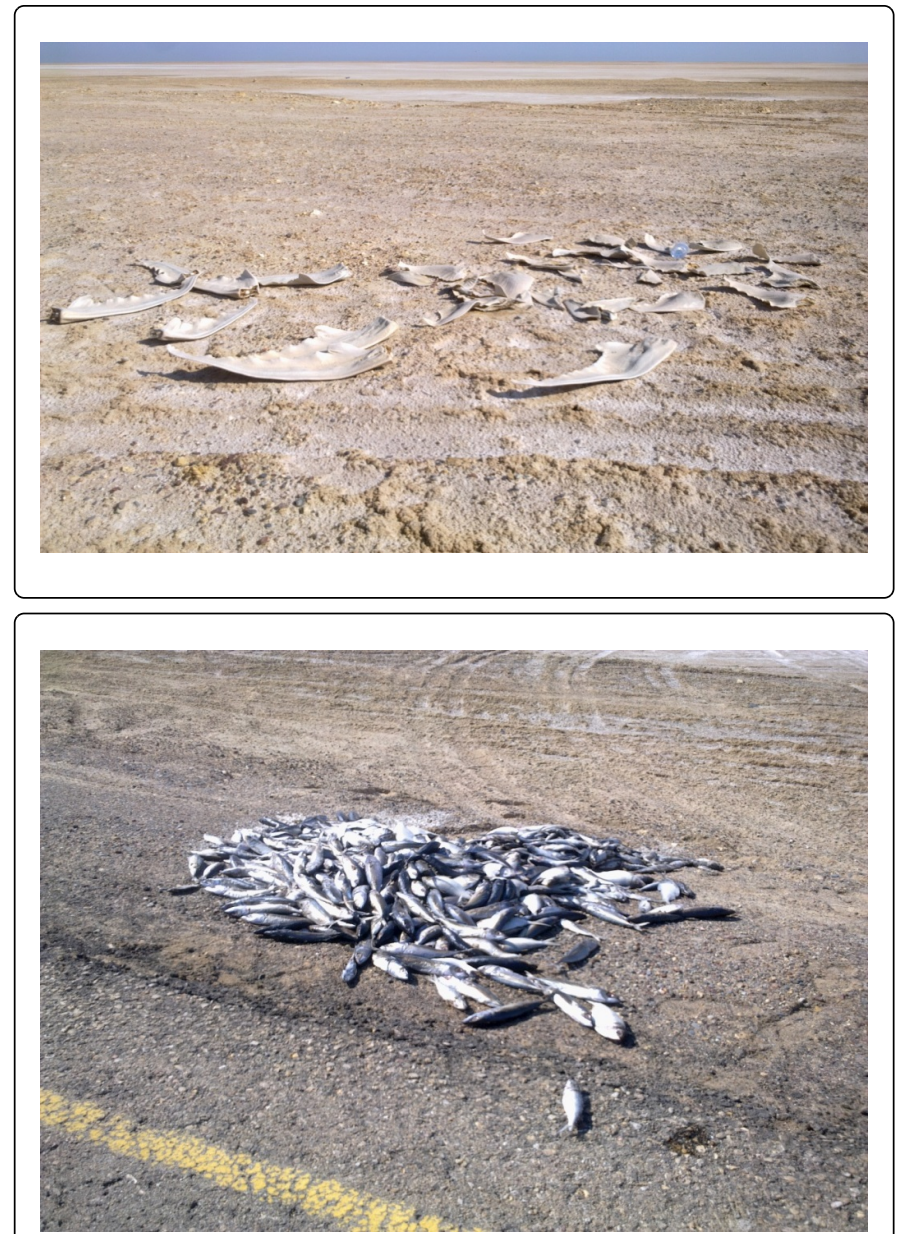

Figure 2 (A,B): Sharks' fins and tails (A), and fish (B) drying aside the national road $\mathrm{nr} 32$ near Al Duqm, Sultanate of Oman (photo by Chiara Giangaspero).

Shark fins are the critical ingredient for shark fin soup, a very important and highly priced traditional, celebratory, Chinese dish. In recent years, due to the dramatic increase in demand for shark products, and for shark fins in particular, some shark populations have been severely targeted, and put under serious threat. While precise estimates are difficult, by some accounts the combined take of elasmobranchs worldwide (including direct fisheries and by catch) has reached nearly 100 million per year [15]. More than 150 countries or territories are involved in the trade. Shark fishing raises a concern for the illegal wasteful practice of "finning", whereby a shark's fins are removed and the remainder of the shark is discarded at sea, considering that the theoretical weight of the fins does not exceed $5 \%$ of the live weight of the shark. However, the major problem is that sharks and rays are generally very vulnerable to overexploitation due to the characteristics of their life cycle, which include slow growth, late maturity and a small number of young. As consequence, their conservation and management has become a global concern [16].

According to the International Union for Conservation of Nature (IUCN), more than $29 \%$ of all pelagic shark species, of which over $50 \%$ are large oceanic-pelagic sharks, are threatened, out of the 477 species known in the world. Nevertheless, only in 2013, the European Union (EU) introduced the banning of the shark finning [17]. Furthermore, 
Page 3 of 3

contradictorily, shark capture is considered a contribution to the economic viability of fisheries, and the blue shark (Priconace glauca) and short fin mako (Isurus oxyrinchus), classified by the IUCN as "near-threatened" and "vulnerable", respectively, are currently the predominant species of shark captured by the EU fishing fleet, with blue shark accounting for approximately $70 \%$ of total reported shark landings [17]. Despite IUCN Red List of Threatened Species (version 2014.1) lists 142 shark species, from "near-threatened" to "critically endangered" [9], only 8 species are included in the Appendix II of the Convention on International Trade in Endangered Species of Wild Fauna and Flora (CITES) [18]. The basking shark (Cetorhinus maximus) and whale shark (Rhincodon typus) Sharks were first included in Appendix II of CITES in February 2003. Currently, a total of eight species of sharks and all manta rays are included in Appendix II (species not necessarily threatened with extinction, but in which trade must be controlled in order to avoid utilization incompatible with their survival), as of June 2013, with effect starting September 2014. However, all species of sawfishes (family Pristidae) are in Appendix I (species threatened with extinction) [18]. Therefore, more effective conservation actions have to be taken to preserve these species which constitute a necessary element of the marine ecosystem.

People sensitization on the value of wildlife and the importance of natural patrimony preservation is an essential element to support conservation efforts, especially for vulnerable and endangered species. Anyone can contribute to reduce the negative phenomenon of poaching on wildlife. Knowledge on wildlife regulations and hunting seasons may be useful to identify violations. If a suspicious activity is remarked, it should be important to inform as soon as possible wildlife authorities, avoiding any confrontation with alleged poachers. Support and good management of wildlife conservation centers, combined with monitoring and repression of crimes against wildlife, represent important aspects in the context of effective conservation strategies. It is important that the wildlife legal frame should be particularly focused on vulnerable and endangered species. In addition, support for development and cooperation focused on creating opportunities among rural defavorized communities may have indirectly a beneficial effect of wild fauna preservation. Wildlife population counting approach, special measures during downturn of economy and digital surveillance to monitor illegal wildlife trade may represent other effective measures to curtail and control the illegal trade of poaching by poor, the traders and the hunters. Furthermore, researches on wildlife conducted in different disciplines such as virology, parasitology or genetic on terrestrial species in the Sultanate of Oman as well as marine species from the Gulf of Oman [19-22] are essential to support preventive strategies in the region.

\section{References}

1. Mace G, Masundire H, Baillie J (2005) Biodiversity. In Ecosystems and Human Wellbeing: Current State and Trends, edited by Coalition and Trends Working Group of the Millennium Ecosystem Assessment, Washington: Island Press, 77-122.

2. Blundell A, Mascia M (2005) Discrepancies in Reported Levels of International Wildlife Trade. Conservation Biology, 19 (6): 2020-2025.
3. Adam D (2010) Monkeys, Butterflies, Turtles. How the Pet Trade’s Greed Is Emptying South- East Asia's Forests. The Guardian, February 212013. www.guardian.co.uk/environment/2010/feb/21/illegal-wildlife-trade (Accessed 20 June, 2014)

4. Rosen GE, Smith KF (2010) Summarizing the evidence on the international trade in illegal wildlife. Ecohealth 7:24-32.

5. Jessica B, Izzo PC (2010) Pets for a Price: Combating Online and Traditional Wildlife Crime Through International Harmonization and Authoritative Polices. William and Mary Environmental Law and Policy Journal, $34(3)$

6. Nijman V (2010) An Overview of International Wildlife Trade from Southeast Asia. Biodiversity Conservation, 19 (4): 1101-1114.

7. Hilton-Taylor C (2009) State of the World's Species. In: Wildlife in a Changing World: An Analysis of the 2008 International Union for Conservation of Nature (IUCN) Red List of Threatened Species, Eds Vie JC, Hilton- Taylor C and Stuart S, IUCN, Gland, Switzerland, 15-42.

8. Rivalan P, Delmas V, Angulo E, Bull LS, Hall RJ, et al. (2007) Can bans stimulate wildlife trade? Nature 447: 529-530.

9. International Union for Conservation of Nature (IUCN) (2014) The IUCN red list of threatened species. Version 2014.1 (http://www.iucnredlist.org) (Accessed on June 20, 2014).

10. Insall DH (2001) Oman. Chapter 10 In: Antelopes: North Africa, the Middle East, and Asia. Global survey and regional action plans, Eds Mallon DP, Kingswood SC, IUCN, Gland, Switzerland.

11. Spalton JA, Lawrence MW, Brend SA (1999) Arabian oryx reintroduction in Oman: successes and setbacks. Oryx, 33 (2): 168-175.

12. Al Jahwari K, Al Rawahi Q (2014) A sand gazelle project launched in $\mathrm{Al}$ Wusta wildlife reserve, Oman. Wildlife Middle East News, 7 (1): 1-3.

13. Vaidya SK (2013) 6 suspect gazelle poachers held in Oman. Gulf News, http://gulfnews.com/news/gulf/oman/6-suspect-gazelle-poachers-held-inoman-1.1204189 (Accessed on June 20, 2014).

14. Food and Agriculture Organization (FAO) (2001) Information on fisheries management in the Sultanate of Oman. http://www.fao.org/fi/ oldsite/FCP/en/omn/body.htm (Accessed on June 20, 2014).

15. Watts S (2000) Finned alive. BBC Wildlife, 18: 35-39.

16. Rose DA (1997) An Overview of World Trade in Sharks and Other Cartilaginous Fishes. Traffic Press, Cambridge.

17. Regulation (EU) No $605 / 2013$ of the European Parliament and of the Council of 12 June 2013 amending Council Regulation (EC) No 1185/2003 on the removal of fins of sharks on board vessels.

18. Convention on International Trade in Endangered Species of Wild Fauna and Flora (CITES) (2013) Current Resolutions and Decisions related to sharks and rays (http://www.cites.org/eng/prog/shark/decisions.php) (Accessed on June 20, 2014).

19. Hussain MH, Ward MP, Body M, Al-Rawahi A, Wadir AA, et al. (2013) Spatio-temporal pattern of sylvatic rabies in the Sultanate of Oman, 2006-2010. Prev Vet Med 110: 281-289.

20. Haseli M (2013) Trypanorhynchcestodes from elasmobranchs from the Gulf of Oman, with the description of Prochristianellagarshaspi n. sp. (Eutetrarhynchidae). SystParasitol 85: 271-279.

21. Mahgoub O, Babiker HA, Kadim IT, Al-Kindi M, Hassan S, et al. (2013) Disclosing the origin and diversity of Omani cattle. Anim Genet 44: 336-339.

22. Maleki L, Malek M, Palm HW (2013) Two new species of Acanthobothrium (Tetraphyllidea: Onchobothriidae) from Pastinachus cf. sephen (Myliobatiformes: Dasyatidae) from the Persian Gulf and Gulf of Oman. Folia Parasitol 60 : 448-456. 